Int. J. Dev. Biol. 54: 1127-1137 (2010)

doi: $10.1387 / \mathrm{ijdb} .093042 \mathrm{ep}$

\title{
Hematopoietic development in the zebrafish
}

\author{
ELIZABETH J. PAIK and LEONARD I. ZON* \\ Stem Cell Program and Division of Hematology/Oncology, Children's Hospital Boston and \\ Dana Farber Cancer Institute, Harvard Medical School, Boston, USA
}

\begin{abstract}
The model organism Danio rerio, also known as the zebrafish, is an excellent system for studying the developmental process of hematopoiesis. It is an ideal model for in vivo imaging, and it is useful for large-scale genetic screens. These have led to the discovery of previously unknown players in hematopoiesis, as well as helped our understanding of hematopoietic development. In this review, we will summarize hematopoiesis in the zebrafish and discuss how genetic approaches using the zebrafish system have helped to build our current knowledge in the field of hematopoiesis.
\end{abstract}

KEYWORDS: hematopoietic stem cell, HSC, hemangioblast, primitive hematopoiesis, definitive hematopoiesis

In the last decade, zebrafish rose as a new genetic system to analyze hematopoietic development. The zebrafish system has a number of unique advantages compared to other vertebrate model organisms. Its embryos are externally fertilized and transparent, enabling in vivo visualization of early embryonic processes ranging from birth of hematopoietic stem cells (HSCs) in the mesoderm to migration of blood cells. In addition, large production of embryos makes phenotype-based forward genetics feasible (de Jong and Zon, 2005). For example, 26 complementation groups with blood defects were identified from two seminal large-scale mutagenesis projects performed in the 1990s (Ransom et al., 1996; Weinstein et al., 1996). Cloning and characterization of these mutants helped us analyze hematopoietic ontogeny and blood-related disease mechanisms. Most importantly, even though sites of hematopoiesis are very different in fish and mammals, the genetic program governing hematopoiesis was found to be highly conserved, which made new knowledge gained from the zebrafish field applicable to mammalian hematopoiesis (Davidson and Zon, 2004).

\section{Overview of vertebrate hematopoiesis}

All vertebrate organisms experience waves of hematopoiesis in their lifetime (Galloway and Zon, 2003). During mammalian and avian development, the first HSCs appear from the blood islands in the extraembryonic yolk sac, giving rise to erythrocytes and macrophages that are required for growing tissues of the embryos (Palis and Yoder, 2001). This primitive wave is only transient, and the successive definitive wave starts intraembryonically in the aorta-gonad-mesonephros (AGM) region. In contrast to primitive HSCs, the definitive HSCs are multipotent, giving rise to all different lineages of blood. Subsequently, HSCs born from the AGM then migrate to the fetal liver where they will proliferate and ultimately seed the bone marrow, which is the adult hematopoietic organ (Cumano and Godin, 2007).

Zebrafish also have waves of hematopoiesis, which occur in a spatially unique manner compared to other vertebrate model organisms (Fig. 1). Its primitive HSCs are born intraembryonically in ventral mesoderm derived tissue called the intermediate cell mass (ICM) (Detrich et al., 1995). During this wave, the anterior part of the embryo generates myeloid cells, while the posterior part generates mostly erythrocytes and some myeloid cells. From 24 hours post-fertilization (hpf), these primitive blood cells start to circulate throughout the embryo. Subsequently, the definitive HSCs emerge from the ventral wall of the dorsal aorta (Thompson et al., 1998; Burns et al., 2002; Kalev-Zylinska et al., 2002), and these HSCs migrate to the posterior region in the tail called the caudal hematopoietic tissue (CHT) (Murayama et al., 2006; Jin et al., 2007). From 3dpf, lymphopoiesis initiates in the thymi. Eventually by $4 \mathrm{dpf}$, HSCs seed the kidney marrow, which is equivalent to bone marrow in mammals. Despite these unique characteristics, zebrafish and other vertebrate animals share genetic pro-

Abbreviations used in this paper:AGM, aorta-gonad-mesonephros region; ALM, anterior lateral mesoderm; AMV, avian myeloblastosis virus; CHT, caudal hematopoietic tissue; dpf, days post-fertilization; etsrp, ets1-related protein; hpf, hours post-fertilization; HSC, hematopoietic stem cell; PLM: posterior lateral mesoderm; scl, stem cell leukemia; YSL, yolk synctial layer.

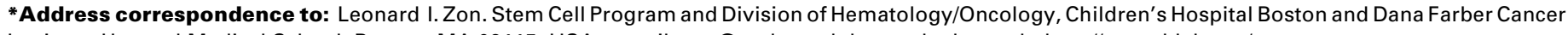
Institute, Harvard Medical School, Boston, MA 02115, USA. e-mail: zon@enders.tch.harvard.edu - web: http://zon.tchlab.org/
}

Final author corrected PDF published online: 14 July 2010.

ISSN: Online 1696-3547, Print 0214-6282 
grams that regulate hematopoiesis. In the following sections, we will explain each step of hematopoiesis and provide an overview of important transcription factors and zebrafish mutants.

\section{Patterning of ventral mesoderm}

Although the first circulating blood cells are visible by 24hpf during zebrafish development, the processes required for HSC generation are already underway from 5hpf, when gastrulation takes place. During the gastrula period, embryos develop three germ layers - ectoderm, mesoderm and endoderm. Among these three germ layers, blood and angioblasts (endothelial progenitors) originate from the mesoderm (Kimmel etal., 1990; Warga and Nusslein-Volhard, 1999).

In zebrafish, the mesoderm arises from the equatorial region above the yolk synctial layer (YSL). The YSL secretes morphogens such as transforming growth factor $\beta$ (TGF $\beta$ ) and fibroblast growth factor (FGF) family members to induce mesoderm and endoderm (Fig. 2A) (Holley, 2006). Mesoderm is first induced by nodal, one of the TGF $\beta$ family members. The importance of nodal signaling in mesoderm induction is seen in mutants called squint and cyclops. These animals have mutations in the nodal-related 1 and 2 genes and the squint;cyclops double mutants are devoid of all mesoderm and endoderm derived tissues except for the tail somites (Feldman et al., 1998).

Once the three germ layers are defined by noda/ signaling, mesoderm is further specified into either dorsal fate (notochord, somites) or ventral fate (blood, vasculature, pronephros). The bone morphogenetic protein (BMP) pathway is one of the most crucial players in this dorsoventral decision (Fig. 2A). Like nodal, BMPs are members of the TGF $\beta$ superfamily. Among multiple BMPs in the zebrafish, bmp2band bmp7are especially important in ventral mesodermal patterning (Kondo, 2007). The swirl(bmp2b) and snailhouse (bmp 7 mutants have a severely dorsalized phenotype and fail to produce ventral mesodermal tissues such as blood and pronephros (Kishimoto et al., 1997; Nguyen et al., 1998; Schmid et al., 2000). On the other hand, when bmp2b is overexpressed during the gastrula period, this results in expansion of erythrocytes (Lengerke et al., 2008). These studies show how bmp2b and bmp7 are necessary and sufficient for blood specification.

\section{Emergence of the hemangioblast}

Starting early during the segmentation period, ventral lateral mesoderm surrounding paraxial mesoderm is further specified into blood, angioblast, and kidney progenitors. Among ventral lateral mesoderm, the anterior lateral mesoderm (ALM) is a major site of primitive myelopoiesis, while the posterior lateral mesoderm (PLM) gives rise to predominantly erythrocytes, as well as some myeloid cells.

From the 2 somite stage, cells co-expressing scl, gata2, Imo2, flit, and etsrp transcription factors appear bilaterally in both the ALM and PLM (Fig. 2B) (Liao et al., 1998; Thompson et al., 1998; Sumanas et al., 2005; Pham et al., 2007). These cells have the potential to become either HSCs or angioblasts, but not kidney
Primitive wave

:
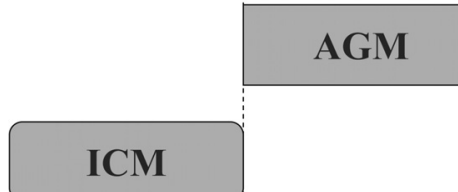

birth of circulation

hemangioblast begins
CHT

Thymus
Definitive wave

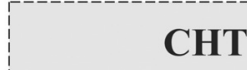

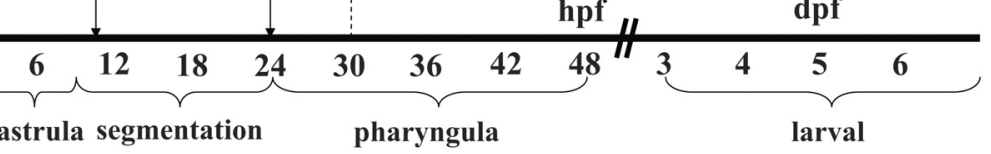

g. 1. The timeline of zebrafish hematopoiesis. (Galloway and Zon, 2003; Davidson and Zon, 2004). ICM=intermediate cell mass; $A G M=$ aorta-gonad-mesoephros region (ventral wall of dorsal aorta); $C H T=$ caudal hematopoietic tissue; pf=hours post-fertilization; $d p f=$ days post-fertilization.

progenitors. This close relationship between HSCs and angioblasts has led to a hypothesis regarding the presence of a common ancestor between them, called the "hemangioblast". This hypothesis was further supported by a zebrafish mutant cloche (described below) that completely lacks both blood and vessels but not other mesodermal organs, and by a single cellresolution fate map study in zebrafish embryos (Stainier et al., 1995; Vogeli etal., 2006). In this fatemap study, it was discovered that there are rare population of cells during early gastrulation that can give rise to HSCs and angioblasts but not to other mesodermal lineages such as heart progenitors (Vogeli et al., 2006).

\section{Transcription factors involved in hemangioblast in- duction}

\section{stem cell leukemia (scl)}

$s c /$ is a basic helix-loop-helix (bHLH) transcription factor which was first discovered at a chromosomal translocation site in leukemic T cells (Brown et al., 1990; Chen et al., 1990). In the mouse embryo it is expressed in hemogenic sites including yolk sac blood islands, fetal liver, and the dorsal aorta (Kallianpur et al., 1994). In addition, Sc/--- embryos are not able to initiate primitive erythropoiesis, indicating its requirement in primitive hematopoiesis (Shivdasani et al., 1995).

The $s c / g e n e$ has also been extensively studied in the zebrafish hematopoiesis field. During zebrafish development, $s c$ is expressed from the 2 to 3 somite stage in the hemangioblast population together with Imo2, gata2 and fli1 (Liao et al., 1998). $s c /$ expression in the ALM persists until the cells in the ALM migrate medially, while its expression in the PLM stays on and is later found in the ICM (Fig. 3A). Additionally, scl+cells appear in the dorsal aorta during definitive hematopoiesis (Liao et al., 1998).

The function of $s c /$ in zebrafish hematopoiesis was studied by 
knockdown approach through morpholino injection. In accordance with the mouse $S c /$ knockout data, knockdown of $s c /$ in zebrafish leads to complete loss of primitive erythropoiesis and myelopoiesis. Also, sc/knockdown leads to loss of $c-m y b$ and runx 1 expression in the dorsal aorta, which implies its importance in definitive hematopoiesis (Dooley et al., 2005; Patterson et al., 2005). In addition to HSC formation, endothelial differentiation is severely disrupted in $s c /$ knockdown embryos. For example, the expression of vascular genes in the dorsal aorta is decreased and intersomitic vessels fail to form in sc/knockdown embryos (Dooley et al., 2005; Patterson et al., 2005). These results indicate that $s c /$ is also required for endothelial differentiation.

\section{gata2}

gata2 is a zinc finger transcription factor which is required for proliferation and maintenance of hematopoietic progenitor cells (Tsai and Orkin, 1997). In mice, Gata2expression is observed in both intraembryonic and extraembryonic sites of hematopoiesis. The importance of Gata2 in primitive hematopoiesis was shown with the early embryonic death of Gata2-/- mice from severe anemia (Tsai et al., 1994).

In zebrafish, gata2 is expressed from the 2 somite stage as two stripes both in the ALM and PLM. Just as scl, Imo2, and fli1, gata2 expression stays on in the ICM (Detrich et al., 1995; Patterson et al., 2005; Patterson et al., 2007). Although gata2 seems to be expressed in the hemangioblast population, gata2 knockdown in zebrafish results in mild defects during primitive hematopoiesis. For example, erythroid specific genes gata1, biklf, globin, and alas2expression stay on in gata2knockdown embryos (Galloway et al., 2005). These results indicate that gata2 may not be essential for zebrafish primitive hematopoiesis, or that other transcription factors may compensate loss of gata2.

Imo2

Imo2 is a LIM domain transcription factor that physically bridges scl and gata2 when they form a DNA-binding complex (Wadman et al., 1997). Like sc/and gata2, Imo2is expressed in hematopoietic progenitors, erythrocytes, and endothelial cells (Fig. 3B). Targeted knockout of $\mathrm{Lmo} 2$ in mice results in embryonic death due to loss of yolk sac erythropoiesis (Warren et al., 1994).

In zebrafish, Imo2 is expressed in the ALM and PLM from the 2 to 3 somite stage, and in the ICM in later stages (Thompson et al., 1998; Zhu et al., 2005). Knockdown of /mo2leads to complete loss of PLM hematopoiesis including primtive erythropoiesis. In addition, Imo2 knockdown partially reduces expression of myeloid gene expression in the ALM. Imo2 knockdown does not affect either sc/or gata2expression (Patterson et al., 2007). This knockdown experiment brings up two possibilities regarding the role of Imo2 in the hemangioblast. First, it may indicate that Imo2 is required for maintaining the hemangioblast population and for differentiation of the hemangioblast into erythrocytes and myeloid cells (Patterson et al., 2007). Conversely, it could also indicate that /mo2acts in parallel to sc/and gata2, and that all three genes are required for erythroid and myeloid differentiation.

\section{fli1}

Fli1 encodes an ETS-domain transcription factor that was first identified by cloning the integration site of the Friend murine leukemia virus in transformed murine erythroleukemia cell lines
(Ben-David et al., 1991). The zebrafish homologue of Fli1, flit, starts to be expressed from the 1 somite stage in the ALM and PLM (Thompson et al., 1998). Its expression stays on in the ICM and later in vascular cells.

When overexpressed, flit can induce ectopic sc/ and Imo2 expression both in the ALM and in the PLM (Liu et al., 2008). Since both sc/and /mo2have several ETS -domain transcription binding sites in their promoters, this led to a hypothesis that flit may work upstream of $s c /$ and Imo2(Zhu et al., 2005). This hypothesis has been difficult to address since morpholino knockdown of single ETS domain transcription factors or a combination of multiple ETS domain transcription factors was insufficient to downregulate either sc/or Imo2(Zhu et al., 2005).

\section{ets1-related protein (etsrp)}

etsrp is an ets domain containing gene which was first identified duing a search for novel vascular genes affected in cloche mutant animals (Sumanas et al., 2005). During zebrafish development, etsrpis expressed bilaterally in both ALM and PLM from the 2 somite stage. Its expression stays on throughout the segmentation period, and it is detected in the ICM and intersomitic vessels by 24hpf (Sumanas and Lin, 2006; Pham et al., 2007).

The function of etsrpwas studied by knocking down the gene
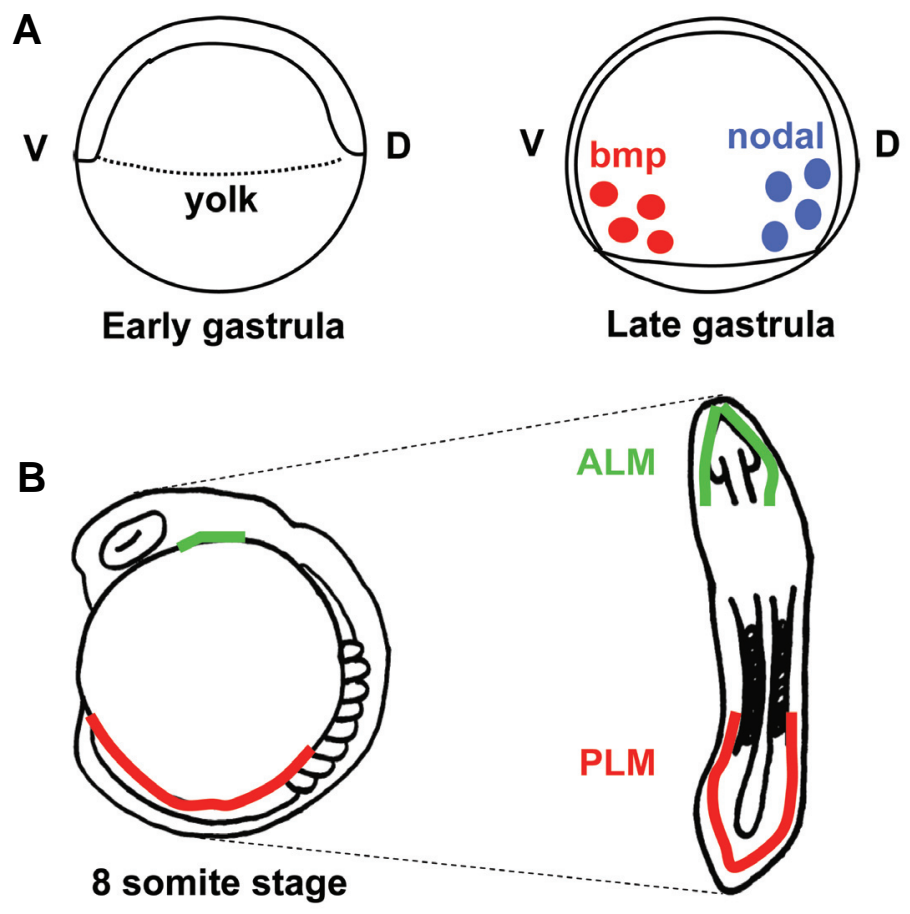

Fig. 2. Patterning of ventral mesoderm and the emergence of hemangioblast. (A) Mesoderm patterning during gastrula period. The bmp and nodal proteins that are secreted from the yolk pattern the mesoderm from early gastrula period. bmps specify ventral fate, while nodals regulate initial mesoderm specification and dorsalization. (B) Emergence of hemangioblast from lateral plate mesoderm. By the segmentation period, the hemangioblast population arises from both ALM (green) and PLM (red). The schematic shows the 8 somite stage embryo and its corresponding flat mounted form, in which the yolk of the embryo is removed. ALM=anterior lateral mesoderm; $P L M=$ posterior lateral mesoderm; $V=$ ventral; $D=$ dorsal. 
through morpholino injection and by characterizing the etsrp mutant animal called $y 11$ (Sumanas and Lin, 2006; Pham et al., 2007). In both studies, etsrp was shown to be required for vascular development. For instance, loss of etsrpaffects expression of endothelial genes including flk1/vegfr2and flt4 (a venous specific gene). In addition, overall vascular structure is severely disrupted when etsrp is knocked down (Sumanas and Lin, 2006; Pham et al., 2007).

In contrast to studies in vascular biology, the role of etsrp in hematopoiesis is yet unclear. In etsrpknockdown studies, it was shown that etsrp specifically regulates ALM myelopoiesis (Sumanas and Lin, 2006; Sumanas et al., 2008). In these studies, etsrp knockdown led to loss of $s c /$ in the ALM, and to loss of myeloid genes including pu. 1 and /-plastin in the ALM. On the other hand, PLM hematopoiesis including erythropoiesis and myelopoiesis was unaffected in these animals (Sumanas and Lin, 2006; Sumanas et al., 2008). Unlike the knockdown studies, the y11 mutant animal had decreased gata1 expression in the PLM (Pham et al., 2007). This discrepancy could be due to differences in the level of etsrpgene expression in knockdown embryos and $y 11$ mutant animals. There was residual etsrp expression in the knockdown embryos, but no expression was detected in $y 11$ mutant animals (Sumanas and Lin, 2006). In these cases, it is possible that ALM myelopoiesis is more sensitive to the level of etsrpgene expression compared to PLM hematopoiesis.

\section{Primitive hematopoiesis}

From the 4 somite stage, the hemangioblast population diverges into either blood cells or angioblasts. Just as primitive myeloid cells emerge from the head of a mammalian embryo, hemangioblasts that are located in the zebrafish ALM become pu. 1+ myeloid progenitors or flk1/vegfr2 + endothelial cells (Bennett et al., 2001; Lieschke et al., 2002). These pu. 1+ myeloid progenitors then migrate to the midline at the 14 somite stage and start to express myeloid specific genes such as /-plastin (/eucocyte-
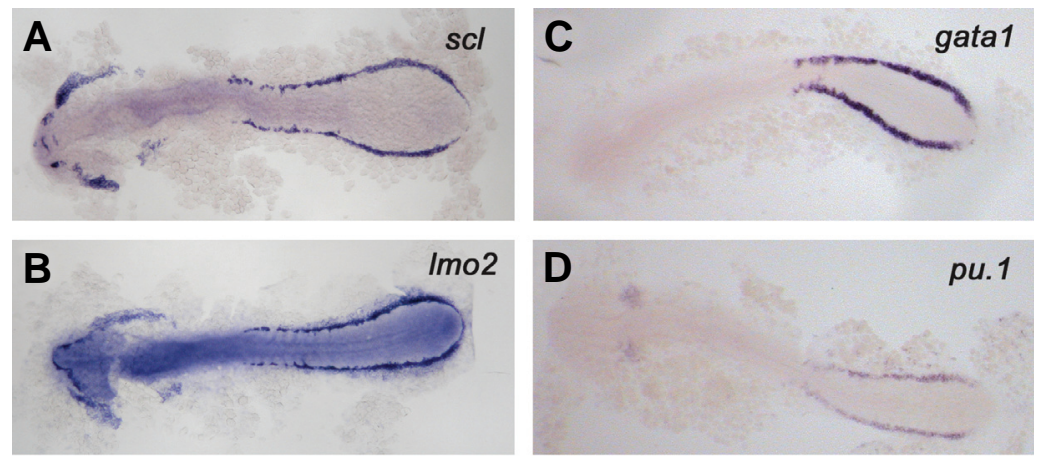

Fig. 3. Expression of hematopoietic genes during primitive hematopoiesis. Whole mount in situ hybridization was performed on the 10 somite stage embryos. (A) Expression of scl. scl is de-

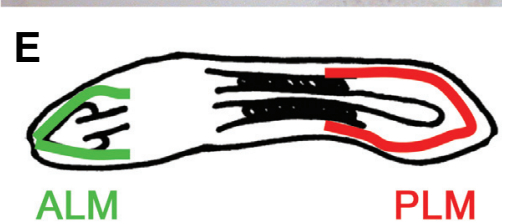

tected both in the ALM and PLM. (B) Expression of Imo2. Imo2 is expressed both in the ALM and PLM. (C) Expression of gata1. Erythropoietic gene gata1 appears mainly in the PLM region. (D) Expression of pu. 1 . Myeloid regulating gene pu. 1 is expressed both in the ALM and in the PLM. (E) Schematic of flatmounted embryo. ALM=anterior lateral mesoderm; PLM=posterior lateral mesoderm. specific plastim, a monocyte/macrophage specific gene) (Herbomel etal., 1999; Bennett etal., 2001; Lieschke etal., 2002). In parallel, the majority of the hemangioblast population in the PLM becomes gata 1+ erythroid progenitors, pu. 1+ myeloid progenitors or endothelial cells (Davidson and Zon, 2004). These bilateral cells in the PLM start to converge to the midline from the 12 somite stage, and eventually form the ICM (Detrich et al., 1995). With the start of the heartbeat at $24 \mathrm{hpf}$, the primitive erythroid progenitors enter circulation and develop into mature erythrocytes, expressing erythroid specific genes such as alas2, carbonic anhydrase, and globin (Brownlie et al., 2003).

\section{Early transcription factors involved in primitive he- matopoiesis}

gata1

gata 1, a zinc finger transcription factor, is a master regulator in erythrocyte development. It has been shown to physically interact with other transcription factors including FOG1 (Friend of GATA1), EKLF (Erythroid Kruppel Like Factor), and PU.1 to name a few (Cantor and Orkin, 2002). Gene targeting studies in mice have initially addressed the essential role of Gata1 in erythropoiesis, since Gata 1-/-mice die during gestation due to failure to differentiate proerythroblasts into mature erythrocytes (Fujiwara et al., 1996). In zebrafish, gata 1 is expressed from the 5 somite stage in the PLM, along with biklf (blood island enriched Kruppel-like factor) in the scl+/mo2+gata2+ population (Detrich et al., 1995; Thompson et al., 1998; Kawahara and Dawid, 2000) (Fig. 3C). From the 12 somite stage, these gata1+ cells migrate medially and start to express erythroid specific genes including globin (Detrich et al., 1995).

In addition to regulating erythroid specific gene transcription, gata 1 suppresses myeloid fate in the ICM. In gata1 knockdown embryos, blood cells in the ICM switch their fate to myeloid cells, expressing pu.1, mpo (myeloperoxidase; granulocyte specific gene) and /-plastin that are normally not detected in erythrocytes (Galloway et al., 2005). There seems to be a crossinhibitory mechanism between gata 1 and pu. 1, as pu. 1 knockdown has a reciprocal effect on ALM myeloid cells (Rhodes et al., 2005) (see below).

\section{pu.1}

pu. 1 is an ETS-domain transcription factor which gets its name from having a PU box binding domain on its $\mathrm{C}$-terminus. It is a master regulator of myeloid cell development, including the development of granulocytes and macrophages (Scott et al., 1994). As a transcription factor, it not only regulates expression of myeloid genes including mpo and /-plastin, but also its own transcription (Chen et al., 1995). In zebrafish, it is expressed from the 6 somite stage in the ALM among the $s c /+/ m o 2+g a t a 2+$ population, and also appears in the ICM from the 10 somite stage (Fig. 3D). This specification of $p u .1+$ cells relies on the bmp signaling pathway. When bmp signaling is repressed by dominant negative bmp receptor, pu. 1+cells fail to appear even though hemangioblast population is present (Hogan et al., 2006). After their emergence, pu. 1+ cells in the ALM migrate towards the midline, then over the 
yolk (Lieschke et al., 2002). These pu. 1+ cells in the ALM and ICM give rise to granulocytes expressing mpoand macrophages expressing /-plastin(Herbomel et al., 1999; Bennett et al., 2001).

Just as gata1+ cells in the ICM can become myeloid cells in the absence of gata1, pu.1+ cells have the potential to become erythrocytes. pu.1 knockdown embryos have ectopic gata 1+ cells in the ALM, and these cells later express alpha-globin, indicating differentiation into erythrocytes (Rhodes et al., 2005). In addition to this 'autonomous' potential of pu. 1+ cells, there also seems to be a non-autonomous cue from the ALM environment driving pu.1+ cells to become myeloid cells. When ALM pu. 1+ cells are transplanted into the ICM of another embryo, these inital ALM cells now become erythroid cells (Rhodes et al., 2005). These examples show there is an interplay between gata1 and pu. 1 transcription factors during primitive hematopoiesis to balance erythroid and myeloid populations.

\section{Definitive hematopoiesis}

The second wave of hematopoiesis, also known as the definitive wave, initiates in the zebrafish embryo from 30hpf. Unlike primitive HSCs, definitive HSCs have the potential to become all blood lineages including lymphocytes. Like in mammals, the first definitive HSCs arise from the ventral region of the dorsal aorta and express runx 1 and c-myb transcription factors (Fig. 4A) (Burns et al., 2002; KalevZylinska et al., 2002). From 48hpf, these $c$-myb+ cells appear in the posterior part of the embryo, known as the caudal hematopoietic tissue (CHT) (Murayama et al., 2006; Jin et al., 2007). The structure of the $\mathrm{CHT}$ highly resembles that of a kidney marrow as it has many sinusoids that slow down the blood flow, and this could help seeding of HSCs (Murayama et al., 2006). The $c-m y b+$ cells later appear in the thymus from 3dpf and in the pronephros from 4dpf (Fig. 4C and 4D) (Murayama et al., 2006; Jin et al., 2007). Thymi and kidney marrow serve throughout the life of a zebrafish, generating adult hematopoietic cells.

HSCs born in the AGM are thought to take two independent routes when they seed the pronephros. The first route involves the $\mathrm{CHT}$, where HSCs first seed the $\mathrm{CHT}$, and then migrate to the pronephros, as shown by photoactivatable tracer experiments (Murayama et al., 2006; Jin et al., 2007). The second route does not involve the CHT. In this case, HSCs in the AGM directly migrate to the pronephros by moving through pronephric tubules as addressed by in vivo imaging of the zebrafish $c$-mybreporter line (Bertrand et al., 2008).

\section{Transcription factors involved in definitive hemato- poiesis}

\section{runx1}

runx 1 is a member of the runt family of transcription factors, which was shown to play roles in many developmental processes from neurogenesis to hematopoiesis (Wang etal., 1996b). RUNX1 has been a focus of many studies since it often appears as a fusion oncogene in leukemia patients (Lutterbach and Hiebert,
AGM
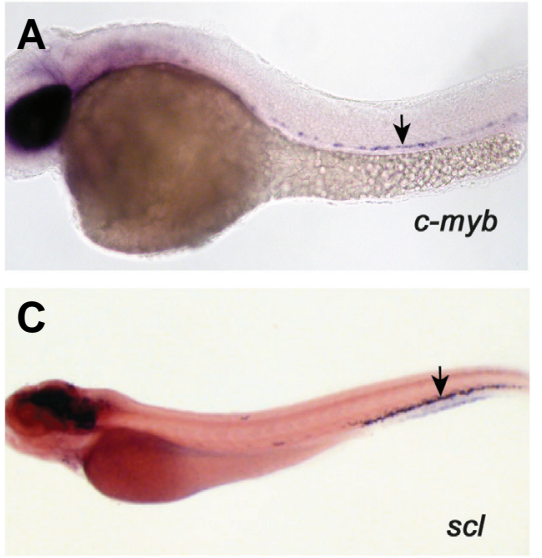

CHT
D

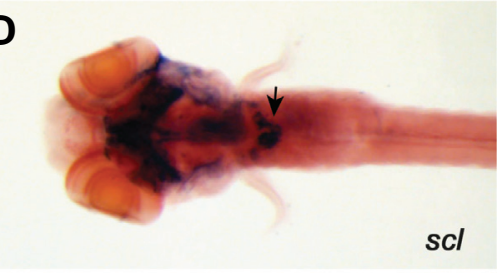

Kidney

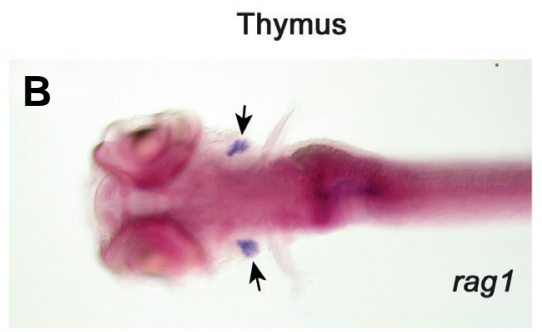

Fig. 4. Sites of definitive hematopoiesis. Whole mount in situ hybridization was different stages of embryos. (A) c-myb expression at 36hpf. The c-myb+ $7 d p f$. The HSCs appear in the pronephros (kidney) from 4dpf, which is equivalent to mammalian bone marrow. AGM=aorta-gonad-mesonephros; $C H T=c a u d a l$ hematopoi-

2000). In mice, Runx 1 is expressed in the ventral region of the dorsal aorta that will become the AGM (North et al., 1999). Also, Runx 1 knockout mice fail to develop definitive erythroid cells, myeloid cells, and lymphoid cells, demonstrating requirement for Runx 1 in definitive hematopoiesis (Okuda et al., 1996; Wang et al., 1996b).

In zebrafish, runx 1 is expressed starting from the 5 somite stage both in the PLM and in the neural tissues. The PLM expression colocalizes with $s c$, indicating runx 1 is also expressed in the hemangioblast population. As definitive hematopoiesis starts, runx 1 is detected in the dorsal aorta (Burns et al., 2002; Kalev-Zylinska et al., 2002; Gering and Patient, 2005). The runx 1 knockdown does not affect primitive erythropoiesis revealing a dispensable role of runx 1 in primitive hematopoiesis (KalevZylinska et al., 2002; Gering and Patient, 2005). In accordance with murine experiments, runx 1 is indispensable for definitive hematopoiesis as $c$-mybexpression decreases with runx 1 knockdown in the dorsal aorta and later lymphopoiesis is also affected (Kalev-Zylinska et al., 2002; Burns et al., 2005; Gering and Patient, 2005).

\section{c-myb}

The myb family of proto-oncogenes encodes transcription factors which were initially discovered in the acutely oncogenic avian myeloblastosis virus (AMV). $c-m y b$, one of the first myb members to be identified, is predominantly expressed in immature hematopoietic cells, and its expression decreases as these cells differentiate (Klempnauer et al., 1982; Westin et al., 1982; Gonda and Metcalf, 1984). The $c-M y b-/$-mouse dies prematurely during gestation due to a failure in fetal liver erythropoiesis despite having normal yolk sac hematopoiesis (Mucenski et al., 1991). This led to the conclusion that $c-M y b$ has a role in definitive hematopoiesis. 
In zebrafish, $c-m y b$ is detected from the 10 to 12 somite stage, when primitive hematopoiesis takes place. However, as shown in mammals, $c$-mybis not required for primitive hematopoiesis, as loss of $c$-mybin zebrafish does not affect expression of gata1, the master regulator of primitive erythropoiesis (Thompson et al., 1998). Around 36hpf, c-myb expression is detected in the ventral wall of the dorsal aorta in the run $x 1+$ cells (Gering and Patient, 2005). From 2dpf, these $c$-myb+ cells appear in the $\mathrm{CHT}$, and eventually migrate to the thymus (from $3 \mathrm{dpf}$ ) and pronephros (from 4dpf) (Murayama et al., 2006; Jin et al., 2007).

\section{ikaros}

The ikaros gene encodes a lymphoid transcription factor which is essential for $B$ and $T$ lymphoid lineage specification (Wang et al., 1996a). It is characterized by having six zinc fingers, which are used in DNA binding and protein-protein interaction (Sun et al., 1996). In mice, Ikaros is detected in all lymphoid cells and in both primitive and definitive hematopoietic precursors (Georgopoulos et al., 1997).

During zebrafish development, ikaros is detected from the primitive wave as two stripes in the ALM and PLM, similar to scl and gata1 (Willett et al., 2001). Then from 2dpf, ikaros is detected in the pharyngeal arch area, indicating ikaros+ cells are migrating towards the thymi. By 3dpf, the ikaros+ cells finally appear in the thymi, which are located just ventral to the developing ear (Willett et al., 2001). These cells start to express rag 1 (recombination activating gene-1) by $4 \mathrm{dpf}$, indicating lymphoid differentiation is taking place (Willett et al., 1997). The role of ikaros in zebrafish lymphopoiesis has been characterized in the ikaros mutant, which will be described below.

\section{Zebrafish hematopoiesis mutants}

Forward genetic screening efforts in zebrafish have yielded many interesting blood related mutants. These mutants were utilized to characterize many aspects of hematopoiesis and to study the role of known blood specific transcription factors. We selected 8 zebrafish mutants to discuss and categorized them into four groups by their defects in hematopoietic ontogeny (Fig. 5).

\section{Mesoderm patterning mutants spadetail (tbx 16)}

spadetailhas a mutation in the $t b \times 16$ gene, which is a member of the T-box transcription factors (Griffin et al., 1998). The T-box transcription factors are downstream of the FGFs, which are secreted from the YSL. The spadetai/mutant has a defect in many mesoderm-derived tissues including blood, despite having normal trunk development (Ho and Kane, 1990; Griffin et al., 1998). The hematopoietic defects are represented by decreased level of scl, Imo2, gata2, fli1, and gata 1expression in the PLM (Thompson et al., 1998; Rohde et al., 2004).

Blastula transplant experiments have shown that $t b \times 16$ regulates hematopoiesis in both autonomous and non-autonomous ways (Rohde et al., 2004). When blastomere cells are transplanted from spadetai/mutant to wildtype animals, the donor cells are unable to give rise to blood cells, indicating the autonomous role of spadetail in hematopoiesis. On the other hand, when wildtype cells are transplanted into spadetail mutant embryos, erythropoiesis only occurs when wildtype cells contribute to both trunk mesoderm and lateral mesoderm (Rohde et al., 2004). This suggests that trunk mesoderm requires tbx16 for inducing hematopoietic progenitors in the lateral mesoderm. Thus, in addition

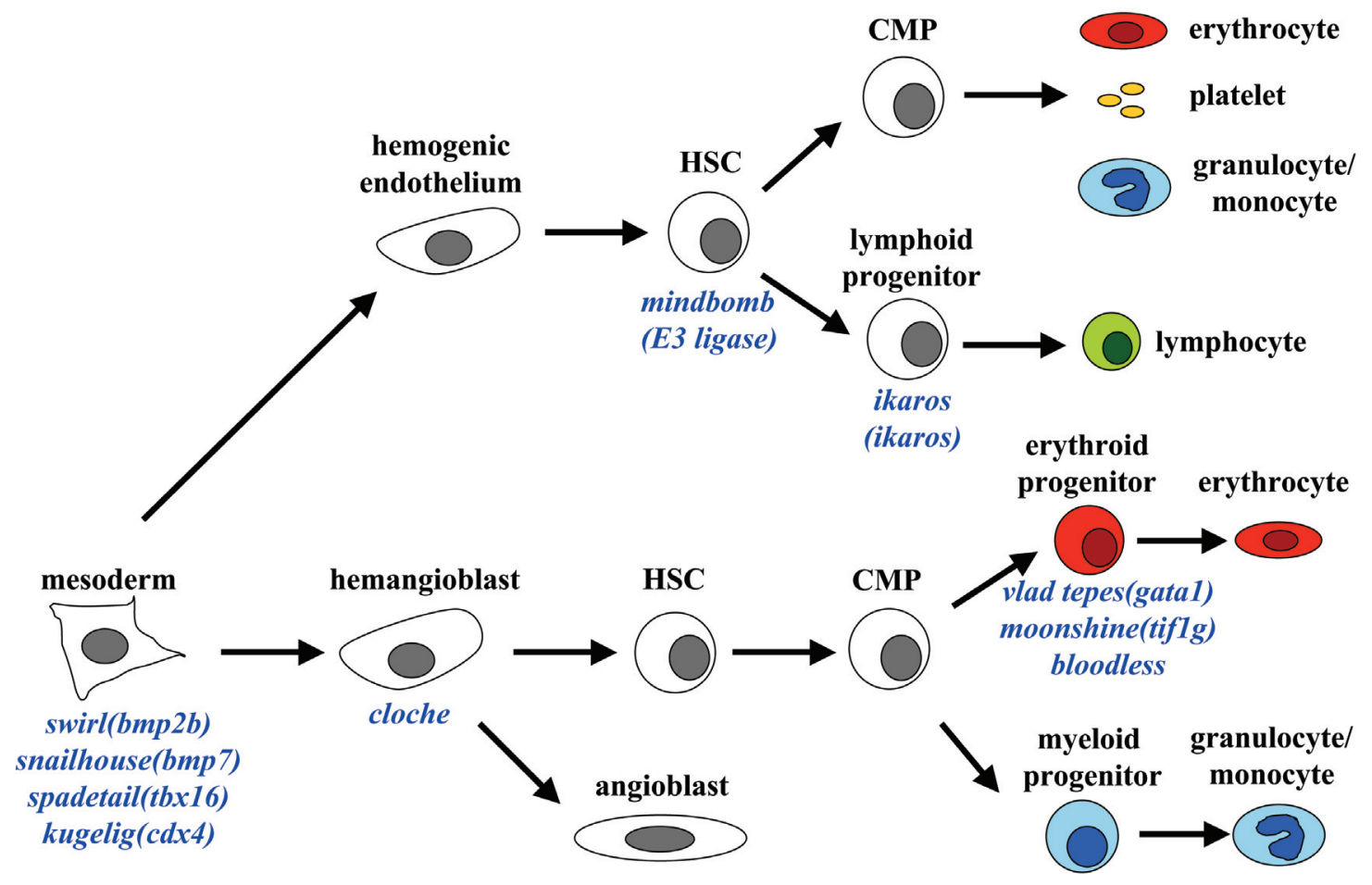

Fig. 5. Overview of zebrafish mutants corresponding to the hematopoietic stage of development. HSC=hematopoietic stem cell; $C M P=$ common myeloid progenitor. 
to autonomous function, spadetailis required nonautonomously during zebrafish hematopoiesis.

\section{kugelig (cdx4)}

kugelig has a mutation in the $c d \times 4$ gene, and it was first identified by its shortened tail (Hammerschmidt et al., 1996). cdx4 is a member of the caudal related family of transcription factors, a family of genes that have been studied for their roles in anteriorposterior patterning (Mlodzik et al., 1985; Edgar et al., 2001). In wildtype zebrafish embryos, $c d \times 4$ expression is detected during gastrulation in the area right above the YSL which will later become ventral mesoderm (Davidson et al., 2003). During segmentation, $c d x 4$ is expressed posteriorly, and its expression transiently overlaps with that of $s c /$ at the 3 somite stage. All of these expression patterns are lost in kugelig mutant embryos (Davidson et al., 2003). In addition, the mutant embryos show low level of sc/and gata 1 at the 5 somite stage and low level of runx 1 at $36 \mathrm{hpf}$, indicative of the role of $c d \times 4$ in primitive and definitive hematopoiesis. Despite these defects, other mesoderm derived tissues including the pronephros and vasculature are relatively normal in kugelig (Davidson et al., 2003; Davidson and Zon, 2006).

Genetically, $c d \times 4$ is downstream of a newly identified bHLH transcription factor mespa. The mespamorphant has hematopoietic defects which are rescuable by $c d x 4$ overexpression (Hart et al., 2007). At the same time, $c d x 4$ is upstream of posterior hox genes, namely hoxb7a and hoxa9a. When hoxb7a and hoxa9a are overexpressed in kugelig mutants, sc/and gata 1 expression is recovered, although the tail defect is still present. This result indicates the hematopoietic defect shown in kugeligis due to the downregulation of hoxgenes in the hematopoietic cell population, rather than due to defects in gross posterior body patterning (Davidson et al., 2003).

\section{Hemangioblast specification mutant cloche (unknown gene)}

cloche was first discovered during a search for spontaneous mutations in an Indonesian fish farm. cloche, meaning 'bell' in French, has a swollen heart due to loss of endocardium (Stainier et al., 1995). The mutation in the cloche gene perturbs the very early stage of hematopoietic and endothelial differentiation as shown with the complete disappearance of $s c /$, Imo2, gata1, /plastin, mpo, and flk1/vegfr2 (Stainier et al., 1995; Liao et al., 1998; Thompson et al., 1998). Through blastula transplantation assays, cloche was shown to regulate hematopoiesis in both autonomous and non-autonomous ways (Parker and Stainier, 1999).

Despite complete absence of hematopoietic and endothelial cells, other mesoderm derived tissues, including the pronephros, are unaffected in cloche (Davidson and Zon, 2004). This led to a hypothesis that the cloche gene is required for hemangioblast specification. Unfortunately, the gene responsible for this mutant has not been cloned to date, due to its telomeric location. Until now, there have been numerous efforts to identify the clochegene by candidate gene searches. Although these studies have not been able to identify cloche, they provided fruitful information about the relationship between other hematopoietic transcription factors and cloche. For example, forced expression of $\mathrm{sc} /$ in cloche mutant animals was able to rescue both erythrocyte and vasculature defects, putting cloche upstream of $s c$ (Liao et al., 1998; Liao et al., 2000). On the other hand, fli1 expression was minimally affected in cloche, putting flit upstream of cloche (Thompson et al., 1998).

\section{tal1 (scl)}

The zebrafish mutant tal1 was identified during a genetic screen looking for genes that affect vasculature development (Bussmann et al., 2007). These animals have a nonsense mutation in the third exon of the $s c / g e n e$. This mutation leads to the loss of the HLH domain required for DNA binding, and the loss of the C-terminus domain which is important in interacting with Imo2 (Patterson et al., 2007). As previously shown by sc/knockdown experiments, the tal1 mutant animals have severe defects in both hematopoietic and endothelial development. They do not initiate either primitive or definitive hematopoiesis, as displayed by loss of gata1, pu. 1 and runx1 expression. In addition, they have defects in endocardial development, due to a failure in endocardial precursor migration (Bussmann et al., 2007). These tal1 mutant animals are anticipated to provide a new tool for studying the role of $s c /$ in hematopoiesis.

\section{Primitive erythroid specification/maintenance mutants vlad tepes (gata1)}

The importance of the gata1 transcription factor in primitive erythropoiesis was shown by a zebrafish mutant called vlad tepes (Weinstein et al., 1996). vlad tepes mutants have a nonsense point mutation in the basic domain located C-terminus to the zinc finger, and they die between 8-15dpf. These mutants initially express some erythroid genes including gata 1 and alpha-globin, but these genes are not detected past 26hpf (Lyons et al., 2002). Part of this defect can be explained by the fact that the mutated form of gata1 loses its ability to bind to promoters of gata 1 target genes such as globin (Lyons et al., 2002). In addition, as shown with gata1 knockdown experiments, the ICM "erythrocytes" in vlad tepes mutants switch fate to myeloid cells and express myeloid genes instead (Galloway et al., 2005).

\section{moonshine (tif $1 \gamma$ )}

The moonshine mutant has a mutation in a chromatin remodeling factor called tif $1 \gamma$ (transcriptional intermediate factor $1 \gamma$ ) (Ransom et al., 2004). It first got its name moonshine from having an excessive amount of pigment cells in the dorsal part of the body (Kelsh et al., 1996). The tif $1 \gamma$ gene is expressed maternally, and by early segmentation period, it is expressed throughout the embryo, and highly enriched in the PLM (Ransom et al., 2004).

In addition to its pigment characteristics, the moonshine mutant has specific defects in primitive and definitive erythropoiesis but normal ALM myelopoiesis. In these embryos, embryonic erythroid specification is present, as shown with normal gata1and $s c /$ expression at the 5 somite stage. The proerythroblast cells however, are progressively lost by apoptotic cell death from the 12 somite stage. As a result, expression of gata1, scl, and gata2 genes are completely absent by 22hpf (Ransom et al., 2004).

Two groups have proposed that mammalian Tif1 $\gamma$ interacts with SMADs which are downstream of TGF $\beta$ pathway. However, the mechanism still remains unclear, since one group proposed Tif1 $\gamma$ may downregulate SMAD4 through ubiquitination, whereas the other group suggested Tif1 $\gamma$ may compete with SMAD4 for 
binding R-SMAD complex (Dupont et al., 2005; He et al., 2006).

\section{bloodless (unknown gene)}

The bloodless mutant zebrafish was first isolated as a spontaneous mutation during an insertional mutagenesis screen. The bloodless mutants do not have circulating erythrocytes until $5 \mathrm{dpf}$, but survive through this anemic stage by relying on oxygen diffusion. Once the blood is recovered, these fish survive to adulthood (Liao et al., 2002).

In the mutant embryos, the $s c /+$ population in the PLM is present during early segmentation, but it is completely lost through apoptosis by $23 \mathrm{hpf}$. In accordance with this, gata 1+ cells are also absent in PLM. On the other hand, ALM myelopoiesis is unaffected and other mesoderm derived tissue such as vasculature and somites are also intact in the bloodlessmutant. This indicates that the bloodless gene solely affects primitive erythropoiesis. By $5 \mathrm{dpf}$, blood cells, possibly from a definitive origin, start to circulate in the mutant embryos, and lymphopoiesis starts at 7dpf (Liao et al., 2002). The mechanism of the bloodless gene is still unclear, and cloning of this gene will help elucidate the difference between the primitive and definitive waves.

\section{Definitive hematopoiesis mutant mindbomb (ubiquitin E3 ligase)}

The mindbomb mutant, which was first studied for its defects in neural development, has a defect in the notch pathway (Itoh et al., 2003). The notchpathway is composed of the transmembrane notch receptor and its ligand delta. When the notch pathway is activated by delta, the intracellular domain of the notch receptor (nicd) translocates into the nucleus, inducing target gene transcription (Gridley, 2007). mindbomb has a defect in generating delta, due to loss of the ubiquitin E3 ligasegene required for delta protein maturation (Itoh et al., 2003).

In addition to its neural defects, mindbomb-/-embryos have defects in definitive hematopoiesis but normal primitive hematopoiesis (Burns et al., 2005). mindbomb mutant embryos have a reduction in runx 1 and $c-m y b$ expression in the dorsal aorta despite having intact vasculature. When the notch pathway is hyperactivated by overexpression of nicd, the number of runx1+C$m y b+$ cells significantly increases in the AGM area. However, when run $x 1$ is downregulated by morpholino injection, ectopic nicd can no longer induce $c$-myb expression in the AGM. In addition, loss of $c$-mybexpression in mindbomb mutant embryo is rescued by runx 1 overexpression. In conclusion, these experiments indicate the notch pathway regulates definitive hematopoiesis, which is mediated by the runx 1 transcription factor (Burns et al., 2005).

\section{ikaros (ikaros)}

The ikaros mutant zebrafish was identified during a search for animals with an absence of lymphopoiesis at $5 \mathrm{dpf}$. ikaros mutant animals have a nonsense mutation in the last exon of the ikaros gene, leading to a truncation of two last zinc fingers which are required for protein-protein interaction (Schorpp et al., 2006).

Characterization of the ikaros mutant suggests that there may be two phases of lymphopoiesis during zebrafish development. The embryonic lymphopoiesis, which happens between $3 \mathrm{dpf}$ and $14 \mathrm{dpf}$, is dependent on the ikaros gene, as shown with absence of rag1 expression in the ikaros mutant during that period. On the other hand, rag1+ cells in ikaros mutant animals appear in thymi from $14 \mathrm{dpf}$, and the mutant fish survive through adulthood. These results indicate that the ikaros gene is absolutely required for embryonic lymphopoiesis, but can be compensated during adult lymphopoiesis by an unknown mechanism (Schorpp etal., 2006).

\section{Conclusion}

Forward genetics screens, targeted gene knockdown by morpholino, and gene overexpression approaches have so far built our knowledge of hematopoietic genes during zebrafish development. In addition to these traditional genetic approaches, a chemical genetic screen was able to isolate many unknown players in hematopoiesis including the prostaglandin pathway (North et al., 2007).

In recent years, the zebrafish field has seen a dramatic increase in the number of available tools. Development of assays such as irradiation recovery and kidney marrow transplantation has provided new ways to examine zebrafish hematopoiesis (Traver et al., 2003; Traver et al., 2004). In addition, a recent success in the reverse genetics approach using zinc finger nucleases and a transposon strategy for generating transgenic zebrafish will help in analyzing roles of additional genes in larval and adult hematopoiesis (Kawakami, 2004; Meng et al., 2008). Finally, a recent generation of 'transparent' adult zebrafish will help our understanding of other aspects of hematopoiesis, including HSC migration and homing processes (White et al., 2008).

\section{Acknowledgements}

We thank Xiaoying Bai, Teresa Bowman, and Michelle Lin for providing images to Fig. 3 and 4, and Xiaoying Bai, Teresa Bowman, Emily Huang, Pulin Li, Michelle Lin, and Alison Taylor for critical reading of this manuscript.

\section{References}

BEN-DAVID Y, GIDDENS EB, LETWIN K, BERNSTEIN A. (1991). Erythroleukemia induction by Friend murine leukemia virus: insertional activation of a new member of the ets gene family, Fli-1, closely linked to c-ets-1. Genes Dev5: 908 918.

BENNETT CM, KANKI JP, RHODES J, LIU TX, PAWBH, KIERAN MW, LANGENAU DM, DELAHAYE-BROWN A, ZON LI, FLEMING MD, LOOK AT. (2001). Myelopoiesis in the zebrafish, Danio rerio. Blood98: 643-651.

BERTRAND JY, KIM AD, TENG S, TRAVER D. (2008). CD41+ cmyb+ precursors colonize the zebrafish pronephros by a novel migration route to initiate adult hematopoiesis. Development 135: 1853-1862.

BROWN L, CHENG JT, CHEN Q, SICILIANO MJ, CRIST W, BUCHANAN G, BAER R. (1990). Site-specific recombination of the tal-1 gene is a common occurrence in human T cell leukemia. EMBO J9: 3343-3351.

BROWNLIE A, HERSEY C, OATES AC, PAW BH, FALICK AM, WITKOWSKA HE, FLINT J, HIGGS D, JESSEN J, BAHARY N, ZHU H, LIN S, ZON L. (2003). Characterization of embryonic globin genes of the zebrafish. Dev Bio/255: 4861.

BURNS CE, DEBLASIO T, ZHOU Y, ZHANG J, ZON L, NIMER SD. (2002. Isolation and characterization of runxa and runxb, zebrafish members of the runt family of transcriptional regulators. Exp Hemato/30: 1381-1389.

BURNS CE, TRAVER D, MAYHALL E, SHEPARD JL, ZON LI. (2005). Hematopoietic stem cell fate is established by the Notch-Runx pathway. Genes Dev 19: 2331-2342.

BUSSMANN J, BAKKERS J, SCHULTE-MERKER S. (2007). Early endocardial morphogenesis requires Scl/Tal1. PLOS Genet 3: e140.

CANTOR AB, ORKIN SH. (2002. Transcriptional regulation of erythropoiesis: an 
affair involving multiple partners. Oncogene 21: 3368-3376.

CHEN H, RAY-GALLET D, ZHANG P, HETHERINGTON CJ, GONZALEZ DA, ZHANG DE, MOREAU-GACHELIN F, TENEN DG. (1995). PU.1 (Spi-1) autoregulates its expression in myeloid cells. Oncogene 11: 1549-1560.

CHEN Q, CHENG JT, TASI LH, SCHNEIDER N, BUCHANAN G, CARROLL A, CRIST W, OZANNE B, SICILIANO MJ, BAER R. (1990). The tal gene undergoes chromosome translocation in $\mathrm{T}$ cell leukemia and potentially encodes a helix-loop-helix protein. EMBO J9: 415-424.

CUMANO A, GODIN I. (2007). Ontogeny of the hematopoietic system. Annu Rev Immuno/25: 745-785.

DAVIDSON AJ, ERNST P, WANG Y, DEKENS MP, KINGSLEY PD, PALIS J, KORSMEYER SJ, DALEY GQ, ZON LI. (2003). cdx4 mutants fail to specify blood progenitors and can be rescued by multiple hox genes. Nature 425 : 300306.

DAVIDSON AJ, ZON LI. (2004). The 'definitive' (and 'primitive') guide to zebrafish hematopoiesis. Oncogene 23: 7233-7246.

DAVIDSON AJ, ZON LI. (2006). The caudal-related homeobox genes cdx1a and $\mathrm{cdx} 4$ act redundantly to regulate hox gene expression and the formation of putative hematopoietic stem cells during zebrafish embryogenesis. Dev Biol 292: 506-518.

DE JONG JL, ZON LI. (2005). Use of the zebrafish system to study primitive and definitive hematopoiesis. Annu Rev Genet 39: 481-501.

DETRICH HW, 3RD, KIERAN MW, CHANFY, BARONE LM, YEE K, RUNDSTADLER JA, PRATT S, RANSOM D, ZON LI. (1995). Intraembryonic hematopoietic cell migration during vertebrate development. Proc Nat/ Acad Sci USA 92: 1071310717.

DOOLEY KA, DAVIDSON AJ, ZON LI. (2005). Zebrafish scl functions independently in hematopoietic and endothelial development. Dev Bio/277: 522-536.

DUPONT S, ZACCHIGNA L, CORDENONSI M, SOLIGO S, ADORNO M, RUGGE M, PICCOLO S. (2005). Germ-layer specification and control of cell growth by Ectodermin, a Smad4 ubiquitin ligase. Cel/121: 87-99.

EDGAR LG, CARR S, WANG H, WOOD WB. (2001). Zygotic expression of the caudal homolog pal-1 is required for posterior patterning in Caenorhabditis elegans embryogenesis. Dev Bio/229: 71-88.

FELDMAN B, GATES MA, EGAN ES, DOUGAN ST, RENNEBECK G, SIROTKIN HI, SCHIER AF, TALBOT WS. (1998). Zebrafish organizer development and germ-layer formation require nodal-related signals. Nature 395: 181-185.

FUJIWARA Y, BROWNE CP, CUNNIFF K, GOFF SC, ORKIN SH. (1996). Arrested development of embryonic red cell precursors in mouse embryos lacking transcription factor GATA-1. Proc Nat/ Acad Sci USA 93:12355-12358.

GALLOWAY JL, WINGERT RA, THISSE C, THISSE B, ZON LI. (2005). Loss of gata1 but not gata2 converts erythropoiesis to myelopoiesis in zebrafish embryos. Dev Cel/8:109-116.

GALLOWAY JL, ZON LI. (2003). Ontogeny of hematopoiesis: examining the emergence of hematopoietic cells in the vertebrate embryo. Curr Top Dev Biol 53: 139-158.

GEORGOPOULOS K, WINANDY S, AVITAHL N. (1997). The role of the Ikaros gene in lymphocyte development and homeostasis. Annu Rev /mmuno/15: 155176.

GERING M, PATIENT R. (2005). Hedgehog signaling is required for adult blood stem cell formation in zebrafish embryos. Dev Cel/8: 389-400.

GONDA TJ, METCALF D. (1984). Expression of myb, myc and fos proto-oncogenes during the differentiation of a murine myeloid leukaemia. Nature 310: 249-251.

GRIDLEY T. (2007). Notch signaling in vascular development and physiology. Development 134: 2709-2718.

GRIFFIN KJ, AMACHER SL, KIMMEL CB, KIMELMAN D. (1998). Molecular identification of spadetail: regulation of zebrafish trunk and tail mesoderm formation by T-box genes. Development 125: 3379-3388.

HAMMERSCHMIDT M, PELEGRI F, MULLINS MC, KANE DA, BRAND M, VAN EEDEN FJ, FURUTANI-SEIKI M, GRANATO M, HAFFTER P, HEISENBERG CP, JIANG YJ, KELSH RN, ODENTHAL J, WARGA RM, NUSSLEIN-VOLHARD C. (1996). Mutations affecting morphogenesis during gastrulation and tail formation in the zebrafish, Danio rerio. Development 123: 143-151.

HART DO, RAHA T, LAWSON ND, GREEN MR. (2007). Initiation of zebrafish haematopoiesis by the TATA-box-binding protein-related factor Trf3. Nature
450: $1082-1085$

HE W, DORN DC, ERDJUMENT-BROMAGE H, TEMPST P, MOORE MA MASSAGUE J. (2006). Hematopoiesis controlled by distinct TIF1gamma and Smad4 branches of the TGFbeta pathway. Cel/125: 929-941.

HERBOMEL P, THISSE B, THISSE C. (1999). Ontogeny and behaviour of early macrophages in the zebrafish embryo. Development 126: 3735-3745.

HO RK, KANE DA. (1990). Cell-autonomous action of zebrafish spt-1 mutation in specific mesodermal precursors. Nature 348: 728-730.

HOGAN BM, LAYTON JE, PYATI UJ, NUTT SL, HAYMAN JW, VARMA S, HEATH JK, KIMELMAN D, LIESCHKE GJ. (2006). Specification of the primitive myeloid precursor pool requires signaling through Alk8 in zebrafish. Curr Bio/16: 506511.

HOLLEY SA. (2006). Anterior-posterior differences in vertebrate segments: specification of trunk and tail somites in the zebrafish blastula. Genes Dev20: 1831 1837.

ITOH M, KIM CH, PALARDY G, ODA T, JIANG YJ, MAUST D, YEO SY, LORICK K, WRIGHT GJ, ARIZA-MCNAUGHTON L, WEISSMAN AM, LEWIS J, CHANDRASEKHARAPPA SC, CHITNIS AB. (2003). Mind bomb is a ubiquitin ligase that is essential for efficient activation of Notch signaling by Delta. Dev Cel/4: 67-82.

JIN H, XU J, WEN Z. (2007). Migratory path of definitive hematopoietic stem/ progenitor cells during zebrafish development. Blood 109: 5208-5214.

KALEV-ZYLINSKA ML, HORSFIELD JA, FLORES MV, POSTLETHWAIT JH, VITAS MR, BAAS AM, CROSIER PS, CROSIER KE. (2002. Runx1 is required for zebrafish blood and vessel development and expression of a human RUNX1-CBF2T1 transgene advances a model for studies of leukemogenesis. Development 129: 2015-2030.

KALLIANPUR AR, JORDAN JE, BRANDT SJ. (1994). The SCL/TAL-1 gene is expressed in progenitors of both the hematopoietic and vascular systems during embryogenesis. Blood 83: 1200-1208.

KAWAHARA A, DAWID IB. (2000). Expression of the Kruppel-like zinc finger gene biklf during zebrafish development. Mech Dev 97:173-176.

KAWAKAMI K. (2004). Transgenesis and gene trap methods in zebrafish by using the Tol2 transposable element. Methods Cel/ Bio/77: 201-222.

KELSH RN, BRAND M, JIANG YJ, HEISENBERG CP, LIN S, HAFFTER P, ODENTHALJ, MULLINS MC, VANEEDEN FJ, FURUTANI-SEIKI M, GRANATO M, HAMMERSCHMIDT M, KANE DA, WARGA RM, BEUCHLE D, VOGELSANG L, NUSSLEIN-VOLHARD C. (1996). Zebrafish pigmentation mutations and the processes of neural crest development. Development 123: 369-389.

KIMMEL CB, WARGA RM, SCHILLING TF. (1990). Origin and organization of the zebrafish fate map. Development 108: 581-594.

KISHIMOTO Y, LEE KH, ZON L, HAMMERSCHMIDT M, SCHULTE-MERKER S (1997). The molecular nature of zebrafish swirl: BMP2 function is essential during early dorsoventral patterning. Development 124: 4457-4466.

KLEMPNAUER KH, GONDA TJ, BISHOP JM. (1982. Nucleotide sequence of the retroviral leukemia gene $\mathrm{v}$-myb and its cellular progenitor c-myb: the architecture of a transduced oncogene. Cel/31: 453-463.

KONDO M. (2007). Bone morphogenetic proteins in the early development of zebrafish. FEBS J274: 2960-2967.

LENGERKE C, SCHMITT S, BOWMAN TV, JANG IH, MAOUCHE-CHRETIEN L, MCKINNEY-FREEMANS, DAVIDSON AJ, HAMMERSCHMIDT M, RENTZSCH F, GREEN JB, ZON LI, DALEY GQ. (2008). BMP and Wnt specify hematopoietic fate by activation of the Cdx-Hox pathway. Cel/ Stem Cel/2: 72-82.

LIAO EC, PAW BH, OATES AC, PRATT SJ, POSTLETHWAIT JH, ZON LI. (1998). SCL/Tal-1 transcription factor acts downstream of cloche to specify hematopoietic and vascular progenitors in zebrafish. Genes Dev 12: 621-626.

LIAO EC, TREDE NS, RANSOM D, ZAPATA A, KIERAN M, ZON LI. (2002. Noncell autonomous requirement for the bloodless gene in primitive hematopoiesis of zebrafish. Development 129: 649-659.

LIAO W, HO CY, YAN YL, POSTLETHWAIT J, STAINIER DY. (2000). Hhex and SCI function in parallel to regulate early endothelial and blood differentiation in zebrafish. Development 127: 4303-4313.

LIESCHKE GJ, OATES AC, PAW BH, THOMPSON MA, HALL NE, WARD AC, HO RK, ZON LI, LAYTON JE. (2002. Zebrafish SPI-1 (PU.1) marks a site of myeloid development independent of primitive erythropoiesis: implications for axial patterning. Dev Bio/246: 274-295. 
LIU F, WALMSLEY M, RODAWAY A, PATIENT R. (2008). Fli1 acts at the top of the transcriptional network driving blood and endothelial development. Curr Bio/18: 1234-1240.

LUTTERBACH B, HIEBERT SW. (2000). Role of the transcription factor AML-1 in acute leukemia and hematopoietic differentiation. Gene 245: 223-235.

LYONS SE, LAWSON ND, LEI L, BENNETT PE, WEINSTEIN BM, LIU PP. (2002. A nonsense mutation in zebrafish gata1 causes the bloodless phenotype in vlad tepes. Proc Nat/ Acad Sci USA 99: 5454-5459.

MENG X, NOYES MB, ZHU LJ, LAWSON ND, WOLFE SA. (2008). Targeted gene inactivation in zebrafish using engineered zinc-finger nucleases. NatBiotechnol 26: 695-701.

MLODZIK M, FJOSE A, GEHRING WJ. (1985). Isolation of caudal, a Drosophila homeo box-containing gene with maternal expression, whose transcripts form a concentration gradient at the pre-blastoderm stage. EMBO J4: 2961-2969.

MUCENSKI ML, MCLAIN K, KIER AB, SWERDLOW SH, SCHREINER CM, MILLER TA, PIETRYGA DW, SCOTT WJ, JR., POTTER SS. (1991). A functional c-myb gene is required for normal murine fetal hepatic hematopoiesis. Cel/65: 677-689.

MURAYAMA E, KISSA K, ZAPATA A, MORDELET E, BRIOLAT V, LIN HF, HANDIN RI, HERBOMEL P. (2006). Tracing hematopoietic precursor migration to successive hematopoietic organs during zebrafish development. Immunity 25: 963-975.

NGUYEN VH, SCHMID B, TROUT J, CONNORS SA, EKKER M, MULLINS MC. (1998). Ventral and lateral regions of the zebrafish gastrula, including the neural crest progenitors, are established by a bmp2b/swirl pathway of genes. Dev Biol 199: 93-110.

NORTH T, GU TL, STACY T, WANG Q, HOWARD L, BINDER M, MARIN-PADILLA M, SPECK NA. (1999). Cbfa2 is required for the formation of intra-aortic hematopoietic clusters. Development 126: 2563-2575.

NORTH TE, GOESSLING W, WALKLEY CR, LENGERKE C, KOPANI KR, LORD AM, WEBER GJ, BOWMAN TV, JANG IH, GROSSER T, FITZGERALD GA, DALEY GQ, ORKIN SH, ZON LI. (2007). Prostaglandin E2 regulates vertebrate haematopoietic stem cell homeostasis. Nature 447: 1007-1011.

OKUDA T, VAN DEURSEN J, HIEBERT SW, GROSVELD G, DOWNING JR. (1996). AML1, the target of multiple chromosomal translocations in human leukemia, is essential for normal fetal liver hematopoiesis. Ce//84: 321-330.

PALIS J, YODER MC. (2001). Yolk-sac hematopoiesis: the first blood cells of mouse and man. Exp Hemato/29: 927-936.

PARKER L, STAINIER DY. (1999). Cell-autonomous and non-autonomous requirements for the zebrafish gene cloche in hematopoiesis. Development 126: 26432651.

PATTERSON LJ, GERING M, ECKFELDT CE, GREEN AR, VERFAILLIE CM, EKKER SC, PATIENT R. (2007). The transcription factors Scl and Lmo2 act together during development of the hemangioblast in zebrafish. Blood 109: 2389-2398.

PATTERSON LJ, GERING M, PATIENT R. (2005). Scl is required for dorsal aorta as well as blood formation in zebrafish embryos. Blood 105: 3502-3511.

PHAM VN, LAWSON ND, MUGFORD JW, DYE L, CASTRANOVA D, LO B, WEINSTEIN BM. (2007). Combinatorial function of ETS transcription factors in the developing vasculature. Dev Bio/303: 772-783.

RANSOM DG, BAHARY N, NISS K, TRAVER D, BURNS C, TREDE NS, PAFFETTLUGASSY N, SAGANIC WJ, LIM CA, HERSEY C, ZHOU Y, BARUT BA, LIN S, KINGSLEY PD, PALIS J, ORKIN SH, ZON LI. (2004). The zebrafish moonshine gene encodes transcriptional intermediary factor 1 gamma, an essential regulator of hematopoiesis. PLOS Bio/2: E237.

RANSOM DG, HAFFTER P, ODENTHAL J, BROWNLIE A, VOGELSANG E, KELSH RN, BRAND M, VAN EEDEN FJ, FURUTANI-SEIKI M, GRANATO M, HAMMERSCHMIDT M, HEISENBERG CP, JIANG YJ, KANE DA, MULLINS MC, NUSSLEIN-VOLHARD C. (1996). Characterization of zebrafish mutants with defects in embryonic hematopoiesis. Development 123: 311-319.

RHODES J, HAGEN A, HSU K, DENG M, LIU TX, LOOK AT, KANKI JP. (2005). Interplay of pu.1 and gata1 determines myelo-erythroid progenitor cell fate in zebrafish. Dev Cel/8: 97-108.

ROHDE LA, OATES AC, HO RK. (2004). A crucial interaction between embryonic red blood cell progenitors and paraxial mesoderm revealed in spadetail embryos. Dev Cel/7: 251-262.
SCHMID B, FURTHAUER M, CONNORS SA, TROUT J, THISSE B, THISSE C MULLINS MC. (2000). Equivalent genetic roles for bmp7/snailhouse and bmp2b/swirl in dorsoventral pattern formation. Development 127: 957-967.

SCHORPP M, BIALECKI M, DIEKHOFF D, WALDERICH B, ODENTHAL J, MAISCHEIN HM, ZAPATA AG, BOEHM T. (2006). Conserved functions of Ikaros in vertebrate lymphocyte development: genetic evidence for distinct larval and adult phases of $\mathrm{T}$ cell development and two lineages of B cells in zebrafish. J Immuno/177: 2463-2476.

SCOTTEW, SIMON MC, ANASTASI J, SINGH H. (1994). Requirement of transcription factor PU.1 in the development of multiple hematopoietic lineages. Science 265: 1573-1577.

SHIVDASANI RA, MAYER EL, ORKIN SH. (1995). Absence of blood formation in mice lacking the T-cell leukaemia oncoprotein tal-1/SCL. Nature 373: 432-434.

STAINIER DY, WEINSTEIN BM, DETRICH HW, 3RD, ZON LI, FISHMAN MC. (1995). Cloche, an early acting zebrafish gene, is required by both the endothelial and hematopoietic lineages. Development 121: 3141-1350.

SUMANAS S, GOMEZ G, ZHAO Y, PARK C, CHOI K, LIN S. (2008). Interplay among Etsrp/ER71, Scl, and Alk8 signaling controls endothelial and myeloid cell formation. Blood 111: 4500-4510.

SUMANAS S, JORNIAK T, LIN S. (2005). Identification of novel vascular endothelial-specific genes by the microarray analysis of the zebrafish cloche mutants. Blood 106: 534-541.

SUMANAS S, LINS. (2006). Ets1-related protein is a key regulator of vasculogenesis in zebrafish. PLOS Bio/4: e10.

SUN L, LIU A, GEORGOPOULOS K. (1996). Zinc finger-mediated protein interactions modulate lkaros activity, a molecular control of lymphocyte development. EMBO J15: 5358-5369.

THOMPSON MA, RANSOM DG, PRATT SJ, MACLENNAN H, KIERAN MW, DETRICH HW, 3RD, VAIL B, HUBER TL, PAW B, BROWNLIE AJ, OATES AC, FRITZ A, GATES MA, AMORES A, BAHARY N, TALBOT WS, HER H, BEIER DR, POSTLETHWAIT JH, ZON LI. (1998). The cloche and spadetail genes differentially affect hematopoiesis and vasculogenesis. Dev Bio/197: 248-269.

TRAVER D, PAW BH, POSS KD, PENBERTHY WT, LIN S, ZON LI. (2003) Transplantation and in vivo imaging of multilineage engraftment in zebrafish bloodless mutants. Nat Immuno/4: 1238-1246.

TRAVER D, WINZELER A, STERN HM, MAYHALL EA, LANGENAU DM, KUTOK JL, LOOK AT, ZON LI. (2004). Effects of lethal irradiation in zebrafish and rescue by hematopoietic cell transplantation. Blood104: 1298-1305.

TSAI FY, KELLER G, KUO FC, WEISS M, CHEN J, ROSENBLATT M, ALT FW, ORKIN SH. (1994). An early haematopoietic defect in mice lacking the transcription factor GATA-2. Nature 371: 221-226.

TSAI FY, ORKIN SH. (1997). Transcription factor GATA-2 is required for proliferation/survival of early hematopoietic cells and mast cell formation, but not for erythroid and myeloid terminal differentiation. Blood89: 3636-3643

VOGELI KM, JIN SW, MARTIN GR, STAINIER DY. (2006). A common progenitor for haematopoietic and endothelial lineages in the zebrafish gastrula. Nature 443: 337-339.

WADMAN IA, OSADA H, GRUTZ GG, AGULNICK AD, WESTPHAL H, FORSTER A, RABBITTS TH. (1997). The LIM-only protein Lmo2 is a bridging molecule assembling an erythroid, DNA-binding complex which includes the TAL1, E47, GATA-1 and Ldb1/NLI proteins. EMBO J16: 3145-3157.

WANG JH, NICHOGIANNOPOULOU A, WU L, SUN L, SHARPE AH, BIGBY M, GEORGOPOULOS K. (1996a. Selective defects in the development of the feta and adult lymphoid system in mice with an Ikaros null mutation. Immunity5: 537 549.

WANG Q, STACY T, BINDER M, MARIN-PADILLA M, SHARPE AH, SPECK NA (1996b. Disruption of the Cbfa2 gene causes necrosis and hemorrhaging in the central nervous system and blocks definitive hematopoiesis. Proc Nat/Acad Sci USA 93: 3444-3449.

WARGA RM, NUSSLEIN-VOLHARD C. (1999). Origin and development of the zebrafish endoderm. Development 126: 827-838.

WARREN AJ, COLLEDGE WH, CARLTON MB, EVANS MJ, SMITH AJ, RABBITTS $\mathrm{TH}$. (1994). The oncogenic cysteine-rich LIM domain protein rbtn2 is essentia for erythroid development. Cel/78: 45-57

WEINSTEIN BM, SCHIER AF, ABDELILAH S, MALICKI J, SOLNICA-KREZEL L, STEMPLE DL, STAINIER DY, ZWARTKRUIS F, DRIEVER W, FISHMAN MC 
(1996). Hematopoietic mutations in the zebrafish. Development 123: 303-309. WESTINEH, GALLO RC, ARYA SK, EVA A, SOUZA LM, BALUDA MA, AARONSON SA, WONG-STAAL F. (1982. Differential expression of the amv gene in human hematopoietic cells. Proc Nat/ Acad Sci USA 79: 2194-2198.

WHITE RM, SESSA A, BURKE C, BOWMAN T, LEBLANC J, CEOL C, BOURQUE C, DOVEY M, GOESSLING W, BURNS CE, ZON LI. (2008). Transparent adult zebrafish as a tool for in vivotransplantation analysis. Cel/Stem Cel/2: 183-189.

WILLETT CE, CHERRY JJ, STEINER LA. (1997). Characterization and expression of the recombination activating genes (rag1 and rag2) of zebrafish. Immunogenetics 45: 394-404.

WILLETT CE, KAWASAKI H, AMEMIYA CT, LIN S, STEINER LA. (2001). Ikaros expression as a marker for lymphoid progenitors during zebrafish development. Dev Dyn 222: 694-698.

ZHU H, TRAVER D, DAVIDSON AJ, DIBIASE A, THISSE C, THISSE B, NIMER S ZON LI. (2005). Regulation of the Imo2 promoter during hematopoietic and vascular development in zebrafish. Dev Bio/281: 256-269. 


\section{Further Related Reading, published previously in the Int. J. Dev. Biol.}

See our recent Special Issue Placenta edited by Joan S. Hunt and Kent L. Thornburg at:

http://www.ijdb.ehu.es/web/contents.php?vol=54\&issue=2-3

Dynamic expression of Endoglin, a TGF-beta co-receptor, during pre-circulation vascular development in chick Cantas Alev, Brendan A.S. Mclntyre, Kanako Ota and Guojun Sheng

Int. J. Dev. Biol. 54: 737 - 742 (2010) (doi: 10.1387/ijdb.092962ca)

Epiblast-derived stem cells in embryonic and adult tissues

Maria P. De-Miguel, Francisco Arnalich-Montiel, Pilar Lopez-Iglesias, Alejandro Blazquez-Martinez and Manuel Nistal Int. J. Dev. Biol. (2009) 53: 1529-1540

A novel role of the glial fate determinant glial cells missing in hematopoiesis Cécile Jacques, Laurent Soustelle, István Nagy, Céline Diebold and Angela Giangrande Int. J. Dev. Biol. (2009) 53: 1013-1022

Developmentally regulated expression of hemoglobin subunits in avascular tissues

Fiona C. Mansergh, Susan M. Hunter, Jenny C. Geatrell, Miguel Jarrin, Kate Powell, Martin J. Evans and Michael A. Wride Int. J. Dev. Biol. (2008) 52: 873-886

Embryonic development of the proepicardium and coronary vessels

Anna Ratajska, Elzbieta Czarnowska and Bogdan Ciszek

Int. J. Dev. Biol. (2008) 52: 229-236

Interleukin-2 induces the proliferation of mouse primordial germ cells in vitro

Cristina Eguizabal, Maria D. Boyano, Alejandro Díez-Torre, Ricardo Andrade, Noelia Andollo, Massimo De Felici and Juan Aréchaga Int. J. Dev. Biol. (2007) 51: 731-738

Tracing the hemangioblast during embryogenesis: developmental relationships between endothelial and hematopoietic cells Thierry Jaffredo, Karine Bollerot, Daisuke Sugiyama, Rodolphe Gautier and Cécile Drevon Int. J. Dev. Biol. (2005) 49: 269-277

Of birds and mice: hematopoietic stem cell development Isabelle Godin and Ana Cumano Int. J. Dev. Biol. (2005) 49: 251-257

Embryonic development of the human hematopoietic system Manuela Tavian and Bruno Péault Int. J. Dev. Biol. (2005) 49: 243-250
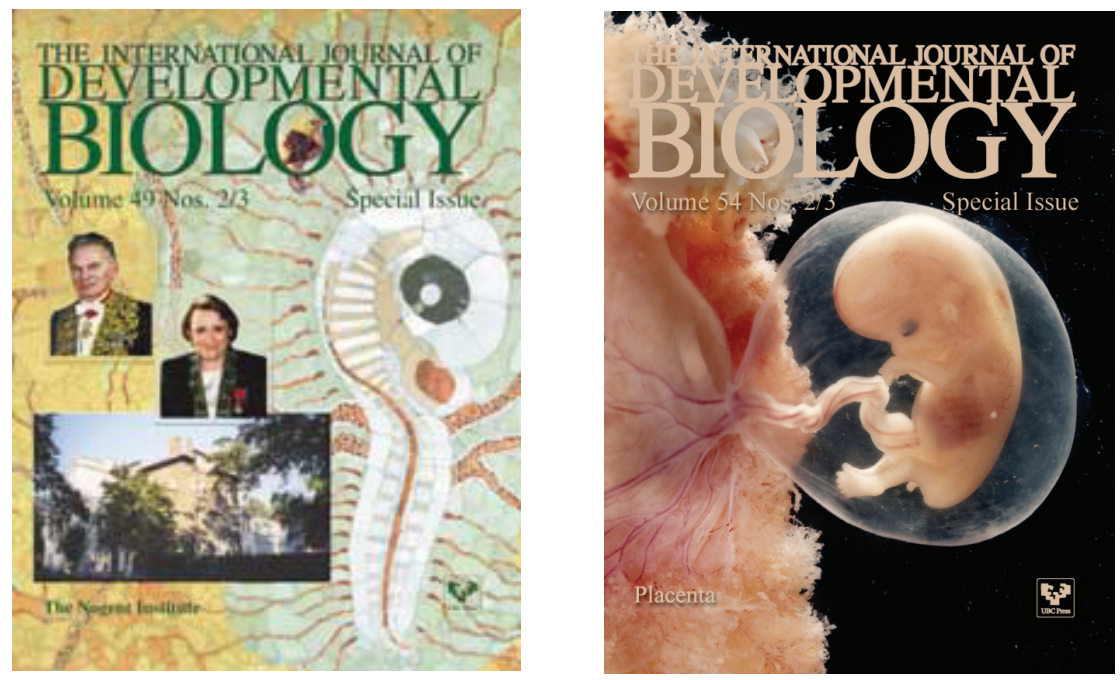

5 yr ISI Impact Factor $(2009)=3.253$

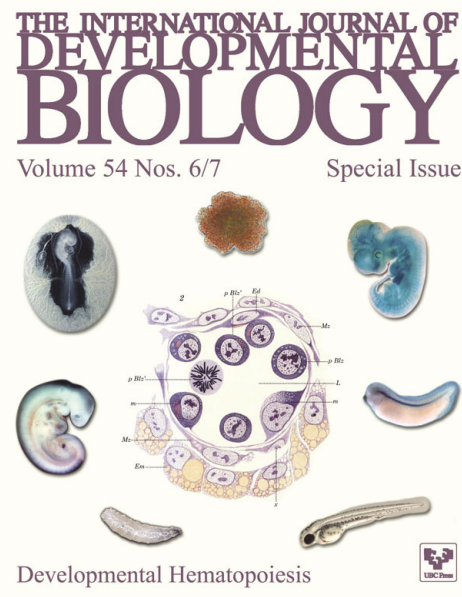

